Dicenda. Estudios de lengua y literatura españolas

ISSN-e: 1988-2556

\title{
Cartografías de lo sobrenatural. Imaginería de terror gótico en la narrativa breve de Patricia Esteban Erlés
}

\author{
Ana Abello Verano ${ }^{1}$
}

Recibido: 26 de enero de 2017 / Aceptado: 6 de noviembre de 2017

Resumen. La producción cuentística de Patricia Esteban Erlés se enmarca en los postulados de la narrativa fantástica más reciente. A través de su mirada lúcida, la escritora zaragozana ha ido construyendo un universo propio donde la poética no mimética se combina con el horror y la amenaza de lo cotidiano. Los resortes que delimitan sus escritos suponen una renovación de los modelos anteriores de la ficción fantástica, pero también retoman diversos motivos de raíz gótica, ya sean narrativos o cinematográficos. La pretensión de este estudio es poner de relieve el papel que esos rasgos góticos de tipo sobrenatural juegan en el desarrollo de las tramas y cómo la autora los emplea para dejar abierto el abismo de la incertidumbre.

Palabras clave: Patricia Esteban Erlés; fantástico; reminiscencias góticas.

\section{[en] Supernatural cartographies. Gothic horror imagery in Patricia Esteban Erlés' short stories}

\begin{abstract}
Patricia Esteban Erlés' short story production belongs to the most recent fantastic narrative approaches. Through her lucid outlook, the Zaragoza writer has gradually created her own universe, in which no mimetic poetics combine with horror and everyday threats. The features that circumscribe her writings turn out to be a renovation of previous fantastic fiction paradigms, but they also recall several motifs from both narrative and cinematographic gothic sources. This study aims to highlight the role these supernatural gothic aspects play in plot developments, and how the author uses them to leave open the abyss of the uncertain.
\end{abstract}

Key words: Patricia Esteban Erlés; fantastic genre; gothic reminiscences.

Sumario: 1. Lo fantástico y lo gótico. Delimitación teórica de dos géneros fronterizos; 2. Patricia Esteban Erlés y los códigos del terror fantástico; 2.1. Reminiscencias góticas de inspiración fílmica; 2.2. Entre fantasmas, monstruos y muñecas de porcelana; 3 . Conclusiones.

Cómo citar: Abello Verano, A. (2019). Cartografías de lo sobrenatural. Imaginería de terror gótico en la narrativa breve de Patricia Esteban Erlés, en Dicenda. Estudios de Lengua y Literatura Españolas, 37, 31-49. 
A Emilio, que lo hizo posible

\section{Lo fantástico y lo gótico. Delimitación teórica de dos géneros fronterizos}

Caracterizado por la problemática confrontación entre lo real y lo imposible, lo fantástico ocupa un lugar de privilegio en el discurso ficcional español de los últimos tiempos. Esta categoría estética pertenece a la literatura de lo insólito o a las formas ajenas al realismo - entre las que se encuentran también lo maravilloso, lo mítico, la ciencia ficción prospectiva o el realismo mágico ${ }^{2}-\mathrm{y}$ presenta una historia encuadrada en una realidad cotidiana que se transgrede ante la incursión de un fenómeno extraordinario ${ }^{3}$. Siempre se tiene que dar esa "irrupción de lo sobrenatural en el mundo real, y sobre todo, la imposibilidad de explicarlo de forma razonable" (Roas, 2001: 18). Pese a ello, se hace necesario mencionar que el empleo discursivo de aquello que está más allá de los límites de la realidad no es válido para ratificar la existencia de literatura fantástica, al menos tal y como se la entiende desde una perspectiva posmoderna. El género de la literatura fantástica strictu sensu comienza su desarrollo en las últimas décadas del siglo XVIII, un periodo histórico marcado por el didactismo y la moralidad. A pesar de esta aparente contrariedad, en el Siglo de las Luces "se dieron las condiciones adecuadas para plantear ese choque amenazante entre lo natural y lo sobrenatural sobre el que descansa el efecto fantástico, puesto que hasta ese momento lo sobrenatural pertenecía al horizonte de expectativas del lector" (Roas, 2001: 21). El movimiento ilustrado repara en lo oculto, en las zonas oscuras de la realidad humana, encontrando recursos expresivos idóneos vinculados al componente preternatural. La fascinación por lo irracional — concretada a nivel ficcional con la aparición de espectros errantes, monjas ensangrentadas, personajes atribulados o víctimas de incidentes inexplicables - empieza a abrirse paso en el seno de los moldes neoclásicos ${ }^{4}$.

Se podría decir que los orígenes de este tipo de manifestación literaria hay que buscarlos en la imperiosa necesidad de reflejar aquellos asuntos que el férreo racionalismo había evitado, y de indagar en lo desconocido con una actitud claramente contestataria. Lo sublime ${ }^{5}$, lo visionario o lo lúgubre se instauran como principios estéticos preferentes en las composiciones de la época. Surge así un género transgresor cuyas muestras

2 Para una mayor profundización en los modos narrativos de la ficción de imaginación, veáse el artículo de Roas (2014).

3 Un marco teórico exhaustivo de lo fantástico puede encontrarse en Todorov (1970), Bessière (1974), Belevan (1976), Jackson (1981), Bozzetto (1998), Ceserani (1999), Herrero Cecilia (2000), Campra (2008) y especialmente en las aportaciones enmarcadas en el siglo XXI de Roas (2001, 2011a).

4 Se puede aseverar, pues, que "esta nueva formar de enfrentar la literatura, se constituye en un movimiento transgresor que intenta transitar por los laberintos más inhóspitos e inexplorados de la conciencia humana lo que le lleva a ganar, de manera instantánea, una legión de seguidores, un público nuevo y agotado por largos años de lecciones edificantes, ensayos políticos y literatura realista en exceso" (López Santos, 2010: 11). Para acceder a la recepción y el desarrollo del género gótico en nuestro país, veáse su estudio monográfico.

5 Edmund Burke, claramente influenciado por filósofos como Descartes o Locke, ahonda en la naturaleza de este término en su Indagación filosófica sobre el origen de nuestras ideas acerca de lo sublime y de lo bello (1757), un escrito de gran repercusión en el marco de la historia de los fenómenos estéticos, convirtiéndose así en punto de referencia indiscutible para la posteridad. Partiendo de un posicionamiento fisiológico y psicológico, y sin olvidar las aportaciones fundacionales del Tratado de lo Sublime de Longino, el teórico irlandés define este concepto como la emoción más fuerte que puede sentir la mente, consecuencia de todo lo que despierta la idea de dolor y peligro, de lo que de algún modo es espantoso o de lo que funciona de manera análoga al terror. Y lo define así porque está convencido de que "las ideas de dolor son mucho más poderosas que aquellas que proceden del placer" (1997: 29). 
creativas empiezan a multiplicarse: el gótico. A través de un código arquitectónico en el que son constantes las abadías de estructura laberíntica, los castillos siniestros, los torreones, los pasadizos o las criptas subterráneas, este tipo de ficción logra romper las expectativas del lector e infundir en él la sensación de estremecimiento. Se convierte en una herramienta discursiva que canaliza temas vedados, que de otro modo serían muy complicados de expresar en la sociedad en que se insertan.

La novela gótica inglesa de la segunda mitad del siglo XVIII reivindicó la fascinación por lo fabuloso en la creación literaria, incorporando el factor extraordinario como parte de la narración y reflejando lo más irracional del ser humano, su maldad, sus deseos encubiertos, su pasión sentimental o sus sueños. Sin embargo, la novela gótica se desarrolla tardíamente en España y en menor cantidad que en otros países europeos, pues el interés por la misma - sin restar mérito a la innovación que conllevó en aspectos que se han mantenido hasta hoy en día, como la búsqueda de lo grotesco y el privilegio del mal en el ser humano- quedó reducido a traducciones de algunos autores representativos y a la incorporación de sus ambientes prototípicos en las producciones, con la preferencia por lo macabro y sombrío, por las muertes violentas o por los escenarios sobrecogedores. Habrá que esperar hasta bien entrado el siglo XIX para que la literatura fantástica empiece a alcanzar cierta independencia como subgénero histórico, convirtiéndose en la manifestación propicia para vencer los límites rígidos de la razón. Las leyes científicas y la capacidad de raciocinio paulatinamente dejan de considerarse los únicos mecanismos para comprender el paradigma de realidad, sustituyéndose por otros medios como la percepción instantánea, la imaginación o incluso la intuición, elementos que ya formaban parte del sentir dual del siglo XVIII. Con la intención de "poner en duda nuestra percepción de lo real" (Roas, 2001: 24) y muy vinculado con el Romanticismo, el relato fantástico se consolida en todas las literaturas occidentales. En España también cobra auge, desarrollándose sin interrupción desde esos inicios decimonónicos hasta la actualidad.

No ha de pasar desapercibido que en el marco de los estudios teóricos sobre lo fantástico, es posible encontrar dos posturas teóricas claramente divergentes: una que sostiene que el género - como entidad evolutiva y dinámica- es heredero de la novela gótica, y otra que, haciéndose eco de la inadecuada flexibilidad en el uso de los conceptos, aboga por una necesaria diferenciación entre gótico y fantástico. En el primer posicionamiento se ubicaría, entre otras, la aportación de Roas, que concibe la novela gótica inglesa como "la primera manifestación literaria del género fantástico" (Roas, 2006: 9), un género que supone así la madurez de esa forma inaugural surgida en la época neoclásica. En contraposición con estas reflexiones, existen investigaciones que recalcan la necesidad de examinar la riqueza inherente al movimiento gótico y desvincularlo por ello del amplio marco de la literatura fantástica. En esa línea se ubican autoras como López Santos y Ordiz Alonso-Collada. Frente a las consideraciones de tipo generalista, esta última clarifica los términos de literatura fantástica y literatura gótica como modos análogos pero necesariamente independientes "y provechosamente analizables tanto en contraposición como en colaboración" (2014: 138) ${ }^{6}$, defendiendo asimismo su continuidad en distintos países desde el siglo XVIII hasta la actualidad. En su pertinente análisis reconoce la complejidad existente a la hora de deslindar los rasgos genuinos de cada tendencia. Aun

Esta investigadora se decanta por el uso del término "fantasía", que recoge discursos no miméticos interrelacionados como la literatura fantástica, la gótica, el realismo mágico, lo maravilloso y la ciencia ficción. 
así, sostiene que lo fantástico se define por la contraposición entre dos dimensiones en el plano ficcional: el mundo que retrata la cotidianidad del protagonista y el mundo de carácter insólito que irrumpe de forma problemática en el marco del primero. Ese asalto de fuerzas desconocidas produce una brecha en el paradigma de realidad y hace que el lector sienta desasosiego, escándalo racional. En cambio, el modo gótico requiere de una evocación del miedo, producido ante los acontecimientos ominosos presentes en el texto; un efecto sin cuya consecución no podría hablarse de este tipo de escritura ${ }^{7}$.

Teniendo en consideración los distintos tratamientos que han generado las ficciones gótica y fantástica, no deben olvidarse los rasgos que en gran medida ambos géneros comparten, entre los que destacan los siguientes: su errónea concepción de literatura al margen del canon establecido, la presencia del elemento sobrenatural que amenaza con subvertir la noción preestablecida de una realidad objetiva, el efecto final de absorbente inquietud, miedo o angustia en los personajes y en el lector, así como diversos mecanismos literarios o ejes temáticos — infracciones en el orden espacial y temporal, dobles, fantasmas, vampiros o confusiones entre la órbita onírica y la vigilia - . Especialmente relevante bajo mi punto de vista se torna su concepción de paraliteratura, puesto que el ámbito crítico y académico ha identificado reiteradamente el realismo con un tipo de producción comprometida. Este prejuicio ha condenado al modo gótico y a lo fantástico - pero también a otras categorías cercanas - a ocupar los parámetros de la literatura de evasión, de la desviación de la norma. Nuestro país se ha caracterizado durante siglos por la poca predisposición que mostraba hacia las expresiones de lo insólito, pero una vez superadas las barreras que relacionaban este tipo de escritura con la literatura infantil y juvenil — restricción que impedía su recepción a un público más amplio-, es posible encontrar creadores cuya producción se encuentra marcada por el elemento distorsionador. Con independencia de que ese empleo de lo irreal sea más recurrente o menos, lo cierto es que los autores contemporáneos se despojan de cualquier complejo compositivo y ven en lo insólito un medio idóneo para plasmar las grietas incomprensibles de la realidad. Lejos de agotarse, las figuraciones góticas y fantásticas han perdurado en el tiempo, adaptándose al momento presente y aunando o intercambiando en muchas ocasiones sus preceptos. Del esquema formulario y la reiteración de motivos se ha evolucionado hacia una variedad de enfoques temáticos y estilos, revalorizando a su vez ambos géneros. Si en esa andadura cronológica, lo fantástico ha visto reactualizados sus principales resortes y estrategias formales - a través de recursos rechazados en épocas pasadas como la parodia o la ironía-, el gótico, por su parte, también ha experimentado un cambio notable, referido sobre todo a sus modos de representación; la exteriorización predominante en el molde clásico da paso a una perspectiva de tipo subjetivo, más psicológica, donde el foco de terror procede del propio individuo.

\section{Patricia Esteban Erlés y los códigos del terror fantástico}

Son muchos los autores que en los inicios del siglo XXI acuden al sustrato gótico en su actividad creativa, tratando de buscar una explicación a las fobias que atormentan

En el mundo anglosajón, el modo gótico experimentó un destacado análisis crítico. Estudios como los de Punter (1980) o Botting (1996) — entre muchos otros que completan el dilatado panorama de investigaciones-, evidencian este auge. 
al ser humano ${ }^{8}$. Dos de ellos son Fernando Iwasaki, con su conocido Ajuar funerario (2004) — donde se reúnen historias terroríficas de inspiración gótica que inciden en los miedos más comunes y en las inseguridades forjadas en la infancia- o Juan Jacinto Muñoz Rengel, que en 88 Mill Lane (2005) ya refleja la influencia del gótico victoriano, una estética a la que recurrirá en otras composiciones posteriores - "La maldición de los Zweeis", por ejemplo, incluido en su segundo volumen de relatos De mecánica y alquimia (2009a)-.

La escritora y profesora Patricia Esteban Erlés forma parte de un nutrido grupo de creadores - la mayoría nacidos entre 1960 y 1975, entre los que se encuentran Carlos Castán, Ángel Olgoso, Pedro Ugarte, David Roas, Félix J. Palma, Óscar Esquivias, Luis Manuel Ruiz o Miguel Ángel Zapata - que ha consagrado su carrera literaria al cultivo de lo fantástico, considerándolo una forma de ruptura ante cualquier certeza ${ }^{9}$. Junto con los de generaciones anteriores que se encuentran todavía en activo como José María Merino o Cristina Fernández Cubas, constituyen voces muy sugerentes en el panorama de la literatura actual y proponen originales vías para explorar la relación entre lo posible y lo imposible. En un intento consciente de renovación, acuden a novedosos tratamientos temáticos y a la hibridación de géneros. Ejemplo de ello es la prosa de la autora zaragozana, que combina en diversas tramas el cultivo de lo fantástico con ciertos vestigios góticos de raíz sobrenatural. La maestría alcanzada por Erlés en la impresión literaria gótica-fantástica radica en su capacidad para relatar los horrores contemporáneos a través de un amplio repertorio de personajes cuya vida se encuentra marcada por el desengaño, la inadaptación y la sed de venganza. Con todo, la supervivencia de los mitos referentes al ideario gótico a lo largo del tiempo se debe a su capacidad versátil y a su constante aproximación a lo cotidiano, un rasgo que acerca sus particularidades "a las descripciones básicas de lo fantástico, dificultando sobremanera la diferenciación entre ambos tipos de literatura" (Ordiz Alonso-Collada, 2014: 146).

No toda la narrativa breve de Patricia Esteban Erlés puede catalogarse de fantástica, ya que existen composiciones de marcado sesgo mimético, pero es cierto que se observa una tendencia llamativa a incluir el efecto propio de esta modalidad en un marco totalmente realista. Lo extraordinario irrumpe sin previo aviso para dejar abierto el abismo de la incertidumbre, haciendo que la realidad de los personajes - y por extensión también la del lector al identificarse con ellos - se vuelva extraña. La autora afirma que emplea este género como forma de protesta ante la normalidad de las cosas y con el fin de "introducir la posibilidad de una puerta distinta a la que se accede a través de la realidad, una fractura de lo cotidiano, una gatera a una dimensión distinta" (en Muñoz Rengel y Roas, 2010: 33). A través de su mirada lúcida, ha ido construyendo un universo figurativo donde los artificios fantásticos, lo macabro y lo inesperado se unen para lograr una literatura de terror psicológico que pone también de manifiesto cuestiones relativas a los estudios de género - materia esta última que, hasta tiempos recientes, no solía ser tratada en las composiciones antimiméticas - Su ópera prima es Manderley en venta (2008a), donde ya están latentes muchos de los motivos que más tarde se convertirán en parte fundamen-

8 López Santos alude a obras de autores como Pilar Pedraza, Eduardo Mendoza, Irene Gracia, Cristina Fernández Cubas y Carlos Ruiz Zafón (2009). En otros trabajos menciona que lo neogótico o el gótico posmoderno es una corriente en alza en el territorio hispanoamericano, encontrando adeptos también en el ámbito español como Manuel Moyano, Miguel Puente Molins, David Torres o José María Merino (2014).

9 Muy significativos en relación con las expresiones de lo fantástico en la actualidad son los estudios de Muñoz Rengel (2009b y 2010) y de Roas (2011b). 
tal de su poética narrativa: espacios domésticos opresivos, testimonios del fracaso existencial, asuntos mortuorios, escenarios de tintes góticos, personajes y voces narrativas principalmente femeninas e historias que inciden en la problemática del sexo femenino. En la misma línea se sitúan sus posteriores libros de relatos - Abierto para fantoches (2008b) y Azul ruso (2010) _ y el ciclo de minificciones Casa de Muñecas (2012) ${ }^{10}$. Asimismo, sus producciones empiezan a ser estudiadas con gran interés desde el ámbito académico $^{11}$, sin olvidar la inclusión de las mismas en diversos volúmenes destinados a abordar el cuento y el microrrelato español actual — entre ellos, Por favor, sea breve 2. Antología de microrrelatos (2009), Perturbaciones. Antología del relato fantástico español actual (2009), Siglo XXI. Los nuevos nombres del cuento español actual (2010), Cuento español actual (1992-2012) (2014) — o antologías temáticas —como Las otras. Una antología de mujeres artificiales (2018), que reúne una muestra significativa de representaciones femeninas desde el molde fantástico y la ciencia ficción-.

Con el fin de mostrar el lado hostil y quizás más inquietante de la realidad, el estilo de Esteban Erlés se concreta en una prosa que busca el detallismo y ahonda en el componente visual, recreando una atmósfera casi cinematográfica. El tratamiento de los personajes constituye el punto fuerte de su escritura, pues a través de ellos se reflejan las inseguridades y los temores más íntimos del ser humano - el fracaso de las idealizaciones, el abandono, el desarraigo, la soledad, la incomprensión, el miedo ante la muerte-, así como el comportamiento que se asume en las relaciones personales - especialmente en las afectivas, marcadas por la actual dinámica de las redes sociales - De este modo, en sus composiciones, como si de un muestrario se tratase, laten las preocupaciones del hombre posmoderno y las particularidades del tiempo presente, tan fragmentario como incierto.

Por otro lado, y haciendo referencia al nivel arquitectónico, la ambigüedad o el efecto sorpresivo reservado para el desenlace de la historia constituyen estrategias ficcionales habituales en sus obras; de ahí que sus composiciones estén siempre destinadas a un lector perspicaz que asuma la tarea de reconstruir el sentido de las mismas. Esta tendencia se hace más visible en los microrrelatos, que invitan al receptor a indagar en los indicios diseminados a lo largo del texto y a reformular su interpretación $^{12}$. Los finales alejados de cualquier evidencia narrativa hacen necesario el proceso de relectura y se relacionan también con la manifestación de la perversión que impera en el ámbito familiar. De acuerdo con ese retrato de lo horrífico, la escritora se encuentra claramente influenciada por Silvina Ocampo o Shirley H. Jackson, a las que, junto con Patricia Highsmith, cita como sus maestras literarias.

\subsection{Reminiscencias góticas de inspiración fílmica}

Los resortes que delimitan los escritos de Esteban Erlés conllevan una profundización en la poética de la ficción fantástica más reciente — renovando la tradición anterior de la que parte con originales propuestas discursivas_-, pero también retoman motivos cinematográficos y narrativos de índole gótica que le permiten seguir

10 La primera novela de la escritora es Las madres negras (2018), que ha merecido el IV Premio Dos Passos.

11 A este respecto pueden consultarse, entre otras, las investigaciones de Sánchez Villadangos (2015), Varga Llamazares (2015) o los trabajos de pretensión comparatista de Sánchez Aparicio (2013) — que estudia conjuntamente la obra de Patricia Esteban Erlés y la de su coetáneo David Roas-, o Encinar (2015), sobre los micrrorrelatos de la autora y de Andrés Neuman.

12 Más detalles sobre los rasgos distintivos del microrrelato en Andres-Suárez (2010). 
indagando en el universo de lo irracional y en la tenue línea que separa el bien del mal. En las páginas que componen Manderley en venta, Abierto para fantoches y, de forma especial, Casa de Muñecas, es posible observar la impregnación de ecos góticos que se actualizan bajo su desbordante imaginación.

En relación con la producción cinematográfica, algunas de sus composiciones establecen un fluido diálogo intertextual con este arte. Esto puede apreciarse desde el evocador título Manderley en venta, un bello homenaje a la mansión protagonista de Rebecca, novela de Daphne du Maurier que fue llevada al cine por el director y productor británico Alfred Hitchoock ${ }^{13}$. No se puede olvidar a este respecto que la película parte de la fórmula del romance y se construye a partir del punto de vista de un personaje femenino, una óptica que interesa mucho a la autora que nos ocupa. Además, se concibe como la primera película del gótico femenino, "género que se configuró en Hollywood durante la década de 1940 y que se caracteriza, más que por conformar una estructura narrativa, por tomar prestado de las novelas góticas de finales del siglo XVIII y principios del XIX una serie de motivos visuales-narrativos y de elementos iconográficos" (Parrondo Coppel, 2007: 79-80). Con independencia del empleo de resortes fácilmente reconocibles como góticos, tanto la obra literaria como el texto fílmico remiten al nombre propio de un personaje, curiosamente el único personaje que no aparece en la película pero cuya presencia es permanente a lo largo de la narración, condicionando sin reparos el proceder de los personajes. Truffaut ya había puesto de relieve esto al postular que el mecanismo de la película "es bastante fuerte: conseguir una opresión creciente únicamente hablando de una muerta, de un cadáver que no vemos nunca" (2016: 136). Dicho aspecto lo potenciará la escritora, demostrando su maestría compositiva y revelando la importancia del espacio y quién lo habita, perceptible desde el edificio humanizado que recoge la portada del libro - una casa con pies y manos que parece suspendida en el aire - hasta la dedicatoria que da paso al último relato del mismo - "A J., porque anoche soñé que volvíamos a Manderley" (2008a: 107) ${ }^{14}$ —, que recalca la vuelta onírica a un espacio añorado ${ }^{15}$.

En el conjunto del volumen, cabe destacar el cuento "Historia de una breve alma en pena", donde una abuela recuerda a su hija muerta a través de su nieta y del enorme caserón de reminiscencias decimonónicas en el que vive. Esteban Erlés menciona que

13 La escritora ha manifestado en reiteradas ocasiones la influencia que la película ejerció en su infancia, momento en el que pudo acceder a la visualización de producciones fílmicas de tintes góticos: "De muy pequeña vi $R e$ beca $[. .$.$] y de alguna forma intuí que en esa película pasaba algo raro, vinculado con esa majestuosa mansión$ llamada Manderley que era casi el fantasma, el reflejo exacto de una mujer muerta y acababa convirtiéndose en personaje principal" (en Muñoz, 2011: 387-388). Lo cierto es que Rebecca ha sido objeto de diversas reescrituras o guiños ficcionales a lo largo del tiempo. Si en el marco español, Erlés rescata el espacio gótico de Manderley para concederle una contextualización moderna, en el ámbito británico y norteamericano también es posible encontrar ejemplos significativos en esa línea: el poemario Manderley, de Rebecca Wolff o la novela Regreso a Manderley, de Sally Beauman.

14 Tanto la obra literaria como la película homónima se inician con la voz de la protagonista anónima recordando su regreso a Manderley: "Soñé anoche que había regresado a Manderley. En este sueño me hallaba ante la verja del parque, pero durante unos instantes no me fue posible entrar. Llamé en sueños al guarda, pero no me contestó nadie y, cuando miré a través de los enmohecidos barrotes de la verja, advertí que la caseta estaba abandonada" (Maurier, 1991: 9). Erlés opta por el empleo de la primera persona de plural para iniciar una trama que aborda el tema del fracaso sentimental y la imposibilidad de regresar al pasado.

15 Los interiores son de suma importancia en el desarrollo de sus historias. La propia escritora señala lo siguiente sobre la dimensión cronotópica: "Supongo que concibo el espacio como cómplice de lo que ocurre entre los personajes, abierto cuando las relaciones fluyen, [...], y cerrado como una concha cuando llega la ruptura. Entonces hay puertas entornadas, armarios vacíos, camas que se abandonan para siempre. Me resulta curioso cómo las personas nos vamos no solo de la vida de alguien, sino también de las habitaciones o las casas que habitábamos poco antes, y cómo los objetos, los espacios, se hacen eco de esa ausencia” (en Muñoz, 2011: 394). 
esta composición condensa todos los argumentos del libro, "el deseo y la culpabilidad, los homenajes a la literatura y cine gótico, el poder de los fantasmas y las casas donde las vidas se nos muestran" (en Muñoz, 2011: 389). La narración llega al lector desde la perspectiva infantil, procedente de la voz de la niña que relata la tortura psicológica — siempre peor que la física — a la que le somete su abuela cada verano, un hecho desconocido por el resto de su familia. Esta abuela maligna trata a su única nieta como si fuera su hija Monsita, cuyo recuerdo - anhelado por una y temido por otra - absorbe todo el escenario; la obliga a dormir en la cama de la difunta, a responder a su nombre y a ponerse sus antiguas prendas infantiles como si de un "decadente ajuar en miniatura" (2008a: 45) se tratase. Pretende asemejarla a alguien que ya no volverá pero que metafóricamente sigue presente, del mismo modo que Maxim de Winter proyecta en su nueva mujer los recuerdos de la primera. La ropa conserva la presencia negativa del muerto y contribuye a la suplantación de identidades, tal y como ocurre en otro relato del libro: "Habitante", donde la protagonista sufre el trasvase de personalidades en el mismo momento en que toca el traje de baño de la antigua dueña de su piso, muerta por ahogamiento en la piscina del edificio. Por medio de sus pertenencias, el personaje inexistente se adueña del espacio recreado.

Respecto al cuento medular de Manderley en venta, es importante reseñar que el extraño comportamiento de la abuela refleja algún tipo de trastorno mental y genera un fuerte impacto emocional en la infancia de su nieta, cuyas palabras subrayan en el siguiente pasaje las secuelas horripilantes que sobre ella opera ese juego de identidades, relacionado con el tránsito hacia una realidad distorsionada y la alteración irreparable del yo:

Sabía que la tía Monsita me vigilaba con sus ojos tristes desde el retrato de la pared, cada vez que entraba en la alcoba de mi abuela para desearle las buenas noches. Por eso procuraba no mirar hacia la cabecera de la cama y salía de allí cuanto antes, aunque sabía que en ningún rincón de la casa lograría librarme de su presencia. Era difícil no pensar en Monsita, sobre todo teniendo en cuenta que mi abuela insistía, verano tras verano, en que ocupara su habitación. Yo no me atrevía a decir nada, pero me daba mucho miedo dormir en la misma cama donde la tía había agonizado, cuarenta años atrás. Además, siempre encontraba frías las sábanas de hilo al acostarme (2008a: 41).

Traumatizada por la tragedia de sobrevivir a una hija - e incapaz de superar esa adversidad - pierde el juicio y resquebraja progresivamente la personalidad de su nieta, eso sí, hasta que se produce su paso a la juventud. Formaría parte de esa galería de personajes quebradizos identificados con el gótico posmoderno, es decir, seres desmoronados "por una serie de vivencias frustrantes que han sido incapaces de superar y que les dificultan su adaptación como seres sociales a la realidad que los envuelve" (López Santos, 2014: 88). Se produce una verdadera desautomatización de la imagen de la abuela y de la bondad que suele asociarse a ella, convirtiéndose en una anciana que logra infundir temor a los de su alrededor — particularidad que emerge de nuevo en "Abuela" y "Sótano", ambas composiciones pertenecientes a Casa de Muñecas_-: "Me aterraba su extrema delgadez de esqueleto, su peinado inmóvil, el diente de oro que centelleaba en uno de los laterales de su boca cada vez que sonreía. Nada escapaba a sus ojos, y yo lo sabía mejor que nadie" (2008a: 44). El hecho de perfilar a la abuela como un ser negativo y el miedo cerval que transmite se 
encuentra en consonancia con la tendencia de Erlés de representar las relaciones femeninas - especialmente los lazos familiares establecidos entre madre-hija, abuelanieta y hermanas - en conflicto y carentes de vínculos afectivos.

El espacio en el que un día vivió la niña muerta, como si de un personaje más se tratara, contribuye a mantener su recuerdo. Cada rincón se encuentra impregnado del espíritu de la tía y urde una red temporal detenida, amortiguada por la tristeza y la desolación vividas. Se muestra así un espacio interior claramente desasosegante; las tramas de la autora casi nunca se desarrollan en espacios abiertos, prevaleciendo el paisaje tenebroso que puede existir de puertas a dentro, "ámbito en el que trascurre la existencia de los personajes" (Álvarez Méndez, 2010: 31). De acuerdo con esta peculiaridad constructiva, se puede afirmar que "el castillo como recinto cerrado, casi herméticamente, dará paso a sanatorios, hospicios o mansiones, como nuevos espacios de la opresión, aislados geográficamente y marginados del conjunto de la sociedad, pero que se descubren como renovados escenarios de pesadilla" (López Santos, 2009: 332). La descripción de la vivienda que lleva a cabo la protagonista sirve para remarcar que la inmersión en ese lugar supone una pérdida absoluta de referentes. Se recurre aquí a la idea del paso límbico o cruce de umbral, potenciado por el fuerte contraste entre el mundo exterior que se abandona y el interior al que se ingresa y donde cualquier convicción previa queda invalidada. Una vez traspasada la puerta, las certezas y las leyes que rigen la realidad se desmoronan y, de forma paralela, la dicotomía exterior/ interior va a tener también su correspondencia en la contraposición entre tiempo presente y tiempo pasado:

En cuanto a la casa del pueblo, sólo puedo decir que hubiera resultado bonita si no hubiera tanta tristeza atrapada entre sus paredes. Era un edificio de tres plantas, que siempre se me antojó fantasmal, como un caballero elegante que nunca se hubiera recuperado de una gran tragedia y permaneciera de espaldas al mundo. En cuanto cruzabas el umbral se adueñaba de ti una implacable melancolía, que parecía flotar en el ambiente igual que el perfume de violetas de mi abuela. La casa siempre estaba en sombras y no se oía ni un alma, porque mi abuela no encendía nunca la televisión Vanguard en blanco y negro y no tenía radio (2008a: 46).

Alejada de cualquier atisbo de civilización, la mansión rural se erige como un espacio que coacciona la libertad y completamente divergente al que la niña debería tener, sumergiéndola así en las tinieblas de una órbita pretérita. El distanciamiento de las coordenadas espacio-temporales propio de las composiciones góticas clásicas -normalmente de evocaciones legendarias o medievales - se ve sustituido aquí por la alteración de la realidad común de la niña, que una vez transgredida la condena a un ambiente tortuoso del que difícilmente puede escapar. Su mundo infantil se ve perturbado ante la imposición de un modo de vida típico de una generación anterior con la que le es imposible identificarse, pero que le conduce a la incomunicación y a la pérdida de identidad.

Las resonancias hitchcockianas vuelven a estar presentes en varias de las imágenes que la artista Sara Morante ideó para complementar los microrrelatos de Casa de Muñecas ${ }^{16}$. La naturaleza espectral de la célebre señora Danvers — esa terrible ama de

16 Las claves narrativas más destacadas de la autora se concentran en las cien historias hiperbreves — no por ello menos intensas - que dan forma a este libro. Además, en la hoja inicial de la obra se plantea una guía de lectura 
llaves que se muestra fiel a su señora — es evidente ya desde la misma portada y parece recordar la hegemonía del pasado. La ilustración muestra tres dimensiones distintas de la misma mujer tras la fachada de una mansión calcinada por las llamas que evoca el comienzo de la película. Manderley simboliza un viaje del este - lo ordenado, lo civilizado - al oeste - la habitación prohibida de Rebeca, una naturaleza desordenada, el acantilado, el yo oculto hacia el que van todos los personajes-. De este modo, la figura de Danvers desaparece en el mismo momento en el que arde el inmueble que custodia, como si fueran dos partes indisociables de la misma unidad. Las tres mujeres se dejan ver a través de grandes ventanales, pero una de ellas tiene el rostro cubierto con una calavera, dando una pista del catálogo de monstruosidades que el lector puede descubrir entre las páginas del libro. En el interior del mismo se incluyen ilustraciones de mujeres que presentan un semblante idéntico o similar al de Danvers - "Traiciones", por ejemplo-y un texto que merece un análisis individual: "Manderley en llamas", sobre la enigmática carbonización que sufre una casa de muñecas de apariencia victoriana que comparten dos hermanas ${ }^{17}$. En ningún momento se explica el origen del fuego, pero el verdadero horror se produce ante el hecho inconcebible de que la única inquilina de la mansión, una miniatura, aparezca ahorcada de la lámpara de su dormitorio. El suspense propio de las producciones filmicas de Hitchcock se impone de nuevo a través de la tensión entre lo animado y lo inanimado y con la prevalencia de un escenario oscuro, cercano al concepto freudiano de "unheimlich" (Freud, 1979: 220), traducido al español como lo ominoso o lo siniestro, es decir, la sensación de inquietante extrañeza que sugiere todo aquello que antes se concebía como familiar o consabido $^{18}$. La actividad autónoma que ha desarrollado esta nueva Olimpia, concretada en su suicidio final, genera el sentimiento de lo ominoso y la sospecha de procesos incomprensibles tras la inmóvil construcción de una casa de muñecas.

\subsection{Entre fantasmas, monstruos y muñecas de porcelana}

Por lo que se refiere al uso de tópicos narratológicos con una función desestabilizadora, la prosa de Erlés refleja un complejo entramado temático de sustrato gótico que, unido a los resortes fantásticos, da lugar a una curiosa propuesta de hibridación genérica. Los paisajes remotos e impresionistas recurrentes en el modelo gótico tradicional - y carentes de verosimilitud en la contemporaneidad - se encuentran en la literatura reciente reemplazados por cronotopos más cercanos al lector, lugares comunes que pueden esconder a su vez fantasmas y traumas inconfesables. Lo que Roland Barthes denomina "efecto de realidad" (1970: 100) — concretado en una ambientación más o menos reconocible - se convierte en un principio estructural, dado que el receptor contrasta los hechos narrados con su experiencia extratextual y eso

acorde con la estructuración arquitectónica de una casa. Cada capítulo se corresponde con una estancia doméstica: "Cuarto de juguetes", "Dormitorio infantil", "Dormitorio principal", "Cuarto de baño", "Salón comedor", "Cocina", "Biblioteca", "Desván de los monstruos", "Cripta" y "Exteriores". Todas estas dependencias configuran una casa de muñecas caracterizada por un halo totalmente misterioso y por un cromatismo de fondo que oscila entre el negro más tétrico y un portentoso magenta, color asociado tradicionalmente al universo femenino.

17 El motivo de la casa de muñecas perfectamente equipada aparecía también en "Historia de una breve alma en pena", como refugio codiciado por la narradora para escapar de la actuación espantosa de su abuela.

18 A lo largo de su análisis del cuento "El hombre de la arena", Freud recoge unas atinadas reflexiones de E. Jentsch sobre la apariencia animada de la muñeca: "Según este autor, una condición particularmente favorable para que se produzca el sentimiento ominoso es que surja una incertidumbre intelectual acerca de si algo es inanimado o inerte, y que la semejanza de lo inerte con lo vivo llegue demasiado lejos" (1979: 233). 
intensifica el "miedo metafísico (o intelectual)"19 (Roas, 2011a: 95) o la sensación de perplejidad perseguidos en este tipo de composiciones.

Con la voluntad de negar una visión objetiva del mundo, por sus páginas transitan dobles, seres metamórficos, objetos insólitos, funestos gatos negros en la línea de $\mathrm{Poe}^{20}$, formulaciones monstruosas y muertos que llaman a la puerta de los vivos haciendo que las fronteras entre el más acá y el más allá se desvanezcan-. Eludiendo los relatos puramente fantásticos en los que se aborda el tema de los intercambios corporales, la yuxtaposición conflictiva de órdenes de lo real, la reencarnación, la cosificación o la humanización de objetos, centraré la atención en dos de los motivos que considero más relevantes: el fantasma, ser intersticial por excelencia, y el monstruo, criatura caracterizada por su versatilidad. El tratamiento de ambos adquiere su potencialidad máxima en Casa de Muñecas, de forma concreta en los capítulos de "Cuarto de juguetes", "Dormitorio infantil", "Desván de los monstruos", "Cripta" y "Exteriores".

Si en la ficción gótica, la irrupción del fantasma se acompaña de un notable efecto maléfico, en la prosa de la zaragozana abundan las visitas de espectros al estilo clásico, como la niña gemela que se niega a irse en "El juego" (Abierto para fantoches) y atormenta la existencia de su hermana, ordenándole que cometa actos atroces sobre su familia ${ }^{21}$. Los personajes sufren el acoso de ese ser imposible que “está más allá de lo real. Más allá de lo humano, y por ello, siempre ha sido la fuente del conflicto y del peligro" (Roas, 2011a: 169). Esto es lo ocurre en "La niña sin madre" (Casa de Muñecas), donde el tema de la orfandad se combina con el terror psicológico que puede producir la presencia del cadáver putrefacto de la madre. La niña le dedica cada noche las siguientes palabras, reflejo del miedo atávico que siente: "Mamita, yo te quiero mucho, pero por favor, no te me aparezcas" (2012: 43). Se intuye que el enfrentamiento o la coexistencia espaciotemporal entre el vivo y el muerto puede provocar "un escalofrío por el espinazo" (Cox y Gilbert, en Roas, 1999: 105), puesto que el ser de ultratumba — al cruzar el espacio liminar que separa dimensiones contrapuestas - siempre amenaza la estabilidad emocional de la persona ante la que se aparece. Lo mismo sucede por la experiencia trágica de la muerte del hermano que vive la protagonista de "Terrores nocturnos" (Casa de Muñecas). Las consecuencias de la pérdida irrecuperable se atisban en una madre que hace diariamente la cama de su hijo muerto, pero es la hermana la que refleja el temor de poder encontrarlo bajo el colchón, desafiando las leyes de la naturaleza como representante de la otredad ${ }^{22}$ :

19 Este término, que el teórico contrapone al de "miedo físico (o emocional)", lo emplea para referirse al efecto genuino de la modalidad fantástica.

20 El gato, que Cirlot asocia con las tinieblas y la muerte (1985: 214), es un animal recurrente en la obra de Erlés. Aparece en "Isobel” y "Tres gatos negros" (ambos de Casa de Muñecas), pero su significación es mayor en "Azul ruso" (Azul ruso), cuyo personaje principal esconde una naturaleza felina tras su apariencia humana, convirtiéndose de este modo en un monstruo por fisión. La fisión es uno de los tropos principales - junto con la fusión, la magnificación, la masificación y la metonimia terrorífica- que permite crear seres intersticiales (Carroll, 2005: 121). Al presentar de forma secuenciada la identidad humana y la identidad del felino, desafía las leyes biológicas y se constituye como una figura terrorífica impura. Un recorrido rigurosamente documentado acerca del valor simbólico que adquiere el gato en diferentes culturas puede encontrarse en Velasco Vargas (2007).

21 La hostilidad entre hermanas puede apreciarse también en "Los zapatos de Margot" (Azul ruso) "El ramo" y "La gemela fea" (estos dos de Casa de Muñecas).

22 Ese temor ante la llegada de la muerte se aprecia también en "Primer plato", del mismo libro. 
Y la muerte ocupó una noche la cama de al lado, que mamá se empeña en hacer todos los días, estirando bien las sábanas y ahuecando el cojín de ganchillo. Sospechas que desde entonces tu hermano está escondido bajo el colchón, lo imaginas temblando de miedo y frío, rodeado de pelusas y descalzo. Pero no te asomas para comprobarlo (2012: 38).

La irrupción de una fuerza inexplicable en la esfera de lo real vuelve a emerger en "Sillas vacías", esta vez con una huérfana al cuidado de una criada de apariencia incorpórea que intuye la amenaza de lo innombrable cuando al dormir observa en su habitación una pared que se puebla "poco a poco de sombras, sintiendo el horror de no poder estar nunca sola del todo" (2012: 88). El fantasma - casi siempre mujer o niña fantasma - se relaciona con traumas pasados y regresa en base a un asunto pendiente que tiene que saldar, muchas veces bajo el tamiz del humor negro y actualizando así su sentido ${ }^{23}$. En efecto, en Casa de Muñecas es posible encontrar niñas que se vengan del acoso escolar sufrido reapareciéndose constantemente ante sus asesinas - "Matando a Alodia" — o muertas que se levantan del féretro para confesarle a su hermana con "una carcajada de ultratumba" (157) la relación que han mantenido en vida con su marido - "Tierra en los ojos" - . La rivalidad fraternal, en este caso, surge por un secreto inconfesable en vida: "Luego volvió a morirse y yo me pasé el resto del velorio con los ojos secos y su mano entre las mías, clavándole el filo de una llave en las palmas hasta que cerraron el féretro" (157).

En otras ocasiones, el fantasma ignora haber abandonado para siempre el mundo de los vivos y pretende vivir tal y como lo hacía antes - los individuos de "Retrato de familia" ilustran muy bien esta circunstancia, puesto que no saben que ahora están "hechos de sábana y hueso" (2012: 87) — o se vincula con relaciones amorosas pasadas, como en "Instrucciones de uso", protagonizado por el fantasma de la ex mujer que se aparece ante la nueva esposa a través del espejo del baño. La superficie reflectante ya no sirve para contrastar la imagen real y la especular; más bien funciona como umbral entre los dos mundos, dado que la muerta le ofrece consejos a la viva y le va dando indicaciones sobre cómo maquillarse y vestirse el día de su boda ${ }^{24}$. Por otro lado, el fantasma que toma la palabra y se convierte en narrador de su propia historia puede poner de relieve las costumbres del más allá — "Día de vivos" — o la soledad inherente a su nuevo estado. "Meditación de la sábana blanca" es un microrrelato paradigmático en este sentido, ya que el narrador va enumerando las desventajas de su condición hasta desembocar en la más nociva: "Lo peor de ser un fantasma es que aquí también estás solo, fantasma para otros fantasmas que llegaron primero" (2012: 136). Otros ejemplos representativos son "Multitud" o "Cineclub", que, mediante la combinación de lo fantasmal y lo erótico, revelan unas relaciones de pareja muy singulares: "Nos gusta filmar películas pornográficas en nuestro dormitorio. Como cuando estábamos vivos" (2012: 65). En las composiciones citadas en las anteriores líneas, el fantasma no encarna una amenaza física drástica y se muestra mucho más

23 Roas sintetiza a la perfección este aspecto al afirmar que "el muerto interrumpe su descanso eterno y vuelve [...] para vengarse de los vivos, atormentándoles en forma de espíritu u otra manifestación sobrenatural semejante (esqueletos animados, cadáveres resucitados). Ya sea porque no se le guarda el debido respeto (o memoria), porque murió antes de cumplir cierta acción o de satisfacer determinada venganza, o para proteger a alguien, lo cierto es que el muerto regresa al mundo de los vivos con la intención de poner las cosas en su sitio" (1999: 94).

24 Otros ejemplos del mismo libro en los que el espejo se convierte en espacio prototípico para las apariciones son "Taxi en el espejo" y "Viuda del suicida". 
humanizado o naturalizado a nivel ficcional, estableciendo de modo simultáneo una mayor empatía con el lector. El narrador ya no se identifica con la víctima que sufre el acoso, sino que ahora es el propio ser fantástico - un recurso que ha empezado a ser muy habitual en los narradores actuales -25 .

En lo que concierne al monstruo - ese ser imposible de clasificar que supone una amenaza no solo de orden físico y psicológico, sino también social y moral-, conviene mencionar que es el motivo más recurrente en la producción de Erlés ${ }^{26}$. Si bien es cierto que hay muchos personajes anodinos que adquieren una dimensión monstruosa, son las figuras femeninas las más destacadas. Su clara inclinación por perfilar estos personajes con un halo de misterio se concreta en el hecho de que muchas veces aparecen configurados como seres malignos, por su fisonomía - la niña deforme de "Seis dedos" (Casa de Muñecas) - , pero sobre todo por sus características psicológicas. Asesinas en serie, hermanas malvadas, esposas que envenenan a sus maridos y madres que infligen castigos horrendos a sus hijas o se deshacen de sus bebés suponen una breve muestra del variado catálogo de mujeres monstruo o mujeres fatales retratadas en su obra. Y es que Erlés forma parte de ese tipo de escritoras que disfrutan "cambiando de lugar los muebles, las cosas, los valores, rompiendo, vaciando estructuras, poniendo patas arriba lo considerado como pertinente" (Cixous, 1995: 61). Desde la madre castradora de "Celebración" (Manderley en venta) —que somete a sus futuras nueras a un exhaustivo y aterrador ritual culinario antes de darle el visto bueno- , a las mujeres tentaculares de gran voracidad sexual que aparecen en "Una y otra" (Manderley en venta), pasando por la enigmática vecina de "Ada Neuman" (Abierto para fantoches) — que es capaz de resquebrajar la unidad de una familia de su edificio-, la practicante de vudú de "Hipotermia" (Casa de Muñecas) - que tortura a la amante de su marido- o la vengadora borgiana Emma Zunz de "Azul ruso" (Azul ruso) — versión moderna de Circe, cuyas víctimas son todos los hombres que cruzan la puerta de su casa-.

Conviene detenerse en uno de los microrrelatos más conocidos y mordaces de la autora, perteneciente a su libro de microrrelatos. Bajo el título de "Centrifugado", se reescriben de forma paródica algunos de los convencionalismos asociados a las tareas de la mujer en el hogar. La protagonista trata de aminorar el enfado de su marido, decapitándole e introduciendo su cabeza en la lavadora. La esposa perfecta no tiene cabida en la prosa de Erlés, solo la mujer atroz y dominante, cuya fuerza reside en la autosuficiencia y la capacidad de ruptura con la escala de valores que tradicionalmente le han sido asignados. No se debe olvidar que bajo su pluma implacable, la autora transgrede con determinación la maternidad y las relaciones simbólicas establecidas entre ciertas dependencias domésticas - la cocina, el dormitorio y el cuarto de baño, especialmente- - y el mundo femenino:

25 Al margen de Casa de Muñecas, en sus volúmenes de relatos se detecta una propensión mayor a la desaparición del efecto terrorífico en la presentación de espectros. Existen cuentos que ponen de manifiesto la dificultad de distinguir entre un lado y otro, como "Hungry for your love" (Azul Ruso) - que presenta a una mujer que vive obsesionada con el regreso a casa de su novio pero que no sabe que es ella la que ha perdido la vida en un trágico accidente de coche- - "Cantalobos" (Manderley en Venta), donde el narrador desconoce su nueva condición y se hace eco de un discurso en primera persona que refleja la vacilación entre diferentes estadios de existencia. Solo al final se descubre que sus palabras surgen del otro lado, provocando el vértigo intelectual tan buscado en este tipo de historias. Un caso muy distinto a los anteriores es "Ouija" (Abierto para fantoches), porque el fantasma es plenamente consciente de su nuevo estado y se comunica con el mundo de los vivos por vía telefónica, aunque el mensaje no llega al destinatario deseado.

26 Más información sobre este motivo en Casas (2012) y Roas (2013). 
La cabeza del hombre que amó da vueltas en el interior de la lavadora, acompañada de una colada de desquiciadas bragas viejas. Ella sonríe cuando se encuentra con sus ojos de ahogado iracundo anegados de jabón, al otro lado del bombo. $Y a$ verás cómo pronto se te pasa el enfado, amor, le dice mientras añade un cazo de suavizante aroma frescor de primavera y programa media hora más de centrifugado (2012: 111).

Como si de una nueva Salomé se tratara, comprueba con agrado, sin ningún dramatismo, que ya no es la colada lo que da vueltas en el tambor de la lavadora, sino su pareja. La mirada de satisfacción de ella contrasta con los ojos de indignación y cólera de él. La heroína gótica confinada en un castillo se transforma ahora en una mujer posmoderna que huye del ambiente claustrofóbico de los espacios cerrados; a nivel textual reniega firmemente de los roles impuestos por el patriarcado y redefine su relación con el hombre en base a alternativas tragicómicas que rozan el absurdo, en consonancia clara con la incongruencia de la sociedad contemporánea. La representación arquetípica de la mujer — basada en la dependencia de la figura masculina en el gótico clásico - se revisa de forma crítica en este relato hiperbreve que emplea conjuntamente el humor y el horror, participando de la categoría estética de lo grotesco $^{27}$. El lector contempla lo estremecedor y lo cómico unidos; la sensación de repulsión ante una cabeza que se separa de su propio cuerpo se complementa con el inevitable efecto irrisorio. En este sentido, la función de lo grotesco se acercaría más a los preceptos góticos puesto que retoma el expresionismo truculento o la estética macabra del género, pero a la vez produce una risa amarga en el lector desconcertado. Se traspasan así los sutiles límites que separan el dominio de lo real y de lo imaginario, y a pesar del fundamento paródico, siempre se produce un apoteósico desenlace que deja entrever el triunfo definitivo del espanto. En contraposición a la existencia de textos donde las connotaciones terroríficas van in crescendo hasta arribar a una catarsis perturbadora, es posible localizar textos de una o dos líneas cuya brevedad no reduce el pavor que suscitan, como "Carne fresca" — "Me gusta abrir el frigorífico y que tú estés ahí" (2012: 104) — o "Toc" — “Cada vez que tu cadáver llama a la puerta finjo desde el otro lado la voz de una niña que está sola en casa" (165)—.

De todo el corpus narrativo de Erlés, es en Casa de Muñecas donde la fusión de lo fantástico y lo gótico se hace más notable — hasta el punto de llegar a confundirse - y donde se pueden localizar distintas manifestaciones de lo monstruoso. El libro se erige así en un ejercicio de imaginería macabra y en muchas composiciones lo grotesco prevalece en detrimento de la dimensión fantástica. Las ilustraciones que aparecen intercaladas entre las minificciones originan un universo simbólico igual de relevante que el texto, contribuyendo a la exaltación de lo ominoso: candelabros, camas vacías, gatos, zapatos de tacón, tijeras, hachas, cabezas de barbies colgadas, armarios tétricos, cunas de bebé, sogas, maletas que nunca llegarán a su lugar de destino, maniquíes cadavéricos, bebidas venenosas, ataúdes o baúles repletos de siniestras muñecas. Más allá de un simple acompañamiento visual, se convierten en

27 Lo grotesco se define como una modalidad "basada en la combinación de lo humorístico y lo terrible, entendiendo éste en un sentido amplio, que incluye lo monstruoso, lo terrorífico, lo macabro, lo escatológico, lo repugnante y lo abyecto" (Roas, 2009: 15). Información más detallada sobre esta categoría puede encontrarse en Roas (2010), un estudio que apuesta por la minuciosa revisión de las teorías de Bajtín y Kayser en relación con esta vía expresiva. 
un elemento paratextual que completa el sentido del texto y logra evocar en el lector el escalofrío final. Texto e imagen se conjugan en la representación de lo abyecto, definido como "the place where meaning collapses" (Kristeva, 1982: 2).

En esa imagen de lo abyecto, las muñecas de porcelana van a jugar un papel destacado al convertirse en fuente de desasoseigo, en un monstruo que desestabiliza por completo la identidad femenina. Estos seres ornamentales aparecen como acompañantes de las protagonistas en su infancia, pero también como modelos idealizados de belleza y origen continuado de complejos y obsesiones, de ahí que se califiquen como pequeñas traidoras. De apariencia inocente, sus perfectos rizos rubios, su sonrisa petrificada y su "mirada de vidrio limpio" (2012: 24) son atributos físicos que les otorgan un cariz escalofriante. A nivel discursivo se potencian sus connotaciones diabólicas mediante el enfrentamiento entre la niña y la muñeca y el miedo a que la segunda conspire contra la primera o pueda llegar a decidir su destino. En efecto, lo que convierte al juguete en un verdadero arquetipo de terror es su posible animación, un proceso que de forma simultánea puede conllevar la progresiva "muñequización" o desaparición de la dueña. Si "Palacio de muñecas" ilustra la dinámica interior de una casa de muñecas y la apariencia humana de sus habitantes al presentarse como criaturas parlantes, "Rosaura", "Muñeca fatal" y, sobre todo, "Traiciones" focalizan la atención en la lucha entre lo artificial y lo natural. En esta última composición, la muñeca se convierte en un ser de carne y hueso, justo en el mismo momento en que la propietaria deja de crecer. Por su parte, en "La mujer de rojo", la animación alcanza su expresión máxima, ya que la intensa actividad nocturna de la muñeca contrasta con la insustancial vida matrimonial de sus dueños. La interacción entre ambas dimensiones es absoluta; el marido observa con complacencia la desnudez de la muñeca y eso ocasiona un ataque de celos en la mujer, que decide destruir la casa. En correspondencia con la notable influencia o el domino absoluto que la muñeca ejerce sobre la rutina de los dueños, puede leerse "Exilio".

Símbolo de inmortalidad, las muñecas recuerdan la frustrada pretensión de cristalizar el tiempo, en orden a un desesperado cuanto vano afán de rejuvenecimiento. De este modo, encarnan estereotipos de los que sus dueñas tratan de liberarse, como se refleja en "Primeras maestras": "Nos enseñaron la muerte y ese día decidimos cambiar las reglas del juego, sonriendo, amables mientras tirábamos hacia atrás un poco más de la cuenta, al cepillar sus lustrosas cabelleras de niñas sombrías" (2012: 24). De hecho, en numerosas ocasiones la maldad procede directamente de las niñas, algo que puede comprobarse en "Holocausto" o "Killer barbies", microrrelato en torno a una niña con instintos asesinos que pone fin a su copiosa colección de muñecas barbies, alentada por su muñeca Nancy. En "Intimidad con el muñeco" se comprueban las dosis de crueldad que estos personajes otorgan a sus pasatiempos, descubriendo lo turbador de sí mismas: "Jugamos. Yo le arranco sus ojos azules y los coloco en la palma de mi mano, como si fueran canicas. Él me cuenta qué ve" (26). El acto no parece propio de una niña, en sintonía con los personajes infantiles que recorren Casa de Muñecas y su caracterización como seres despiadados que ejercen toda su crueldad sobre sus juguetes y quienes les rodean - incluidas sus amigas, como sucede en "Rosebud"-.

La óptica de Erlés, como ella misma corrobora, implica "una mirada malévola, que tiende a ensañarse y configura a los personajes a través de referencias crueles" (en Muñoz, 2011: 395). La monstruosidad infantil y las pulsiones homicidas siempre están presentes, ya sea explícitamente —exponente magnífico es la niña retratada en 
"Anas", que mata a todas las compañeras de colegio con las que comparte nombreo de forma sugerida. En esta última línea, las gemelas huérfanas de "El resplandor" - título homónimo de la famosa película de Kubrick — son devueltas por sus padres adoptivos al orfanato, un acto reincidente que permite intuir su naturaleza adorable y temible a un tiempo. Las actuaciones maléficas sugeridas se retoman en "Asado de domingo" e "Indulto", dejando al lector la tarea de imaginar el terrible desenlace que en ambos casos le espera a la abuela.

\section{Conclusiones}

Desde los inicios de su carrera literaria, Esteban Erlés ha empleado el género fantástico como medio "para explorar y representar todo aquello que se nos escapa de la realidad y de la compleja interioridad del ser humano" (Roas, 2011b: 296). Ese uso de lo fantástico como cauce de expresión habitual, a veces fluctúa y se hibrida con el imaginario gótico, lo terrorífico y lo grotesco, cuyos ecos se perciben principalmente a nivel arquitectónico —-mediante espacios lúgubres y envolventes que suscitan sensaciones de misterio - y en relación con la caracterización fantasmal y monstruosa de los personajes femeninos. Todo este entramado discursivo entronca con las tendencias literarias no realistas, cuya presencia es mayor en el panorama narrativo actual. Lejos de concebirse con un sentido escapista o meramente superficial, las diferentes modalidades de lo insólito esconden una honda crítica sobre nuestra escurridiza realidad, tal y como demuestran las composiciones de la autora que mediante el contraste entre un ámbito cotidiano y el mundo de lo extraño enfrentan al lector a continuos interrogantes. A ello se unen la parodia, la ironía y el humor negro, estrategias de índole transgresora que además de otorgar un broche de oro a los textos, hacen evolucionar los moldes genéricos.

Los recursos de tamiz gótico utilizados para evocar el miedo intensifican el efecto de realidad, puesto que presentan un mundo intratextual donde surge sin previo aviso la delectación en lo horrible y macabro. Esa grieta de lo inesperado que se abre a nivel ficcional y resquebraja la noción de normalidad aparente se relaciona con la mente impredecible del individuo, la experiencia de la muerte - que provoca tanto miedo como fascinación-, la pervivencia de espectros emocionales, el descubrimiento de oscuras amenazas o la disolución de cualquier frontera. Ya no hay escenas de barbarie o torturas en el subsuelo de un castillo encantado. Las ruinas son exteriores e interiores y ya no es posible la restauración del orden. El sufrimiento se desencadena en un mundo cotidiano donde todo es posible y donde el origen del mal proviene de la propia naturaleza humana. Todo ello pone de relieve la dicotomía entre el yo que estimamos ser y el lado perverso o la conciencia ensangrentada que escondemos y a veces sale a luz, demostrando una vez más que la realidad puede ser algo más perturbador de lo que parece a simple vista.

\section{Obras citadas}

Álvarez Méndez, Natalia, “Territorios, parajes y contornos literarios: Aproximación teórica al espacio en la narrativa actual", en María Pilar Celma Valero y José Ramón González (eds.), Lugares de ficción. La construcción del espacio en la narrativa actual, Valladolid, Cátedra Miguel Delibes, 2010, pp. 17-38. 
Andres-Suárez, Irene, El microrrelato español. Una estética de la elipsis, Palencia, Menoscuarto, 2010.

Barthes, Roland, "El efecto de realidad", en Lo verosimil, Buenos Aires, Tiempo contemporáneo, 1970, pp. 95-101.

Beauman, Sally, Regreso a Manderley, Barcelona, Salamandra, 2002.

Belevan, Harry, Teoría de lo fantástico. Apuntes para una dinámica de la literatura de expresión fantástica, Madrid, Anagrama, 1976.

Bessière, Irène, Le récit fantastique. La poétique de l'incertain, Paris, Larousse Université, 1974.

Botting, Fred, The New Critical Idiom, London, Routledge, 1996.

Bozzetto, Roger, Territoires des fantastiques. Des roman gothiques aux récits d'horreur moderne, Aix-en-Provence, Publications de l'Université de Provence, 1998.

Burke, Edmund, Indagación filosófica sobre el origen de nuestras ideas acerca de lo sublime $y$ de lo bello, Madrid, Editorial Tecnos, [1757] 1997.

Campra, Rosalba, Territorios de la ficción: lo fantástico, Sevilla, Renacimiento, 2008.

Carroll, Noël, Filosofía del terror o paradojas del corazón, Madrid, Antonio Machado, [1999] 2005.

Casas, Ana (ed. y pról.), Las mil caras del monstruo, Barcelona, Bracket Cultura, 2012.

Ceserani, Remo, Lo fantástico, Madrid, Visor, 1999.

Cirlot, Juan Eduardo, Diccionario de símbolos, Barcelona, Labor, 1985.

Cixous, Hélène, La risa de la medusa. Ensayos sobre la escritura, Barcelona, Editorial Anthropos, [1975] (1995).

Encinar, Ángeles (ed.), Cuento español actual (1992-2012), Madrid, Cátedra, 2014.

—, "La fragmentariedad tragicómica y de terror: los microrrelatos de Andrés Neuman y Patricia Esteban Erlés", en Ottmar Ette, Dieter Ingenschay, Friedhelm Schmidt-Welle y Fernando Valls (eds.), MicroBerlín: de minificciones y microrrelatos, Madrid-Frankfurt, Iberoamericana-Vervuert, 2015, pp. 217-234.

Esteban Erlés, Patricia, Manderley en venta, Zaragoza, Tropo Editores, 2008a.

-, Abierto para fantoches, Zaragoza, Diputación Provincial de Zaragoza, 2008b.

-, Azul ruso, Madrid, Páginas de Espuma, 2010.

-, Casa de Muñecas, Madrid, Páginas de Espuma, 2012.

-, Las madres negras, Madrid, Galaxia Gutenberg, 2018.

Freud, Sigmund, "Lo ominoso", en James Strachey y Anna Freud (eds.), Obras completas. Vol. XVII: De la historia de una neurosis infantil (el "Hombre de los Lobos") y otras obras (1917-1919), Buenos Aires, Amorrortu Editores, [1919] 1979, pp. 219-251.

Herrero Cecilia, Juan, Estética y pragmática del relato fantástico, Cuenca, Ediciones de la Universidad de Castilla-La Mancha, 2000.

Hitchcock, Alfred, Rebecca, Londres, Fremantle, 1940.

Iwasaki, Fernando, Ajuar funerario, Madrid, Páginas de Espuma, 2004.

Jackson, Rosemary, Fantasy, the literature of subversion, New York, New Accents, 1981.

Kristeva, Julia, Powers of Horror, New York, Columbia University Press, 1982.

López-Pellisa, Teresa (ed.), Las otras. Una antología de mujeres artificiales, León, Eolas Ediciones, 2018.

López Santos, Miriam, “Los viejos fantasmas vuelven al presente: lo gótico en la literatura española actual", Estudios Humanísticos. Filología, 31 (2009), pp. 321-334.

—, La novela gótica en España (1788-1833), Vigo, Academia del Hispanismo, 2010.

- "La deconstrucción del inconsciente: Reminiscencias góticas en la narrativa mexicana actual", en Javier Ordiz (ed.), Estrategias y figuraciones de lo insólito en la narrativa mexicana (siglos XIX-XXI), Berna, Peter Lang, 2014, pp.81-101. 
Maurier, Daphne du, Rebeca; La posada de Jamaica, Barcelona, Planeta, [1938] 1991.

Muñoz, Miguel Ángel, La familia del aire. Entrevistas con cuentistas españoles, Madrid, Páginas de Espuma, 2011.

Muñoz Rengel, Juan Jacinto, 88 Mill Lane, Granada, Alhulia, 2005.

—, De mecánica y alquimia, Madrid, Salto de Página, 2009a.

-, ed. y pról., Perturbaciones. Antología del relato fantástico español actual, Madrid, Salto de Página, 2009b.

—, "La narrativa fantástica en el siglo XXI", en David Roas y Ana Casas (coords.), Ínsula: revista de letras y ciencias humanas, 765 (2010), pp. 6-10.

Muñoz Rengel, Juan Jacinto y Roas, David, "Los escritores ante lo fantástico", en David Roas y Ana Casas (coords.), Ínsula: revista de letras y ciencias humanas, 765 (2010), pp. 28-34.

Obligado, Clara, ed., Por favor, sea breve 2. Antología de microrrelatos, Madrid, Páginas de Espuma, 2009.

Ordiz Alonso-Collada, Inés, "Estrategias ficcionales de lo insólito: la literatura gótica frente a la literatura fantástica", Babedec, 2.6 (2014), pp. 138-168.

Parrondo Coppel, Eva, “La mujer' en el cine gótico: Rebeca (Rebecca, Alfred Hitchcock, 1940)", Trama y fondo: revista de cultura, 19 (2007), pp. 79-92.

Pellicer, Gemma, y Vals, Fernando (eds.), Siglo XXI. Los nuevos nombres del cuento español actual, Palencia, Menoscuarto, 2010.

Punter, David, The Literature of Terror, London, Longman, 1980.

Roas, David, "Voces del otro lado: el fantasma en la narrativa fantástica", en Jaume Pont (ed.), Brujas, demonios y fantasmas en la literatura fantástica hispánica, Lleida, Universitat de Lleida, 1999, pp. 93-107.

—, ed., Teorías de lo fantástico, Madrid, Arco/Libros, 2001.

- De la maravilla al horror. Los inicios de lo fantástico en la cultura española (17501860), Vigo, Mirabel, 2006.

—, "Poe y lo grotesco moderno", $452^{\circ} \mathrm{F}$. Revista electrónica de teoría de la literatura y literatura, 1 (2009), pp. 15-27.

—, "La risa grotesca y lo fantástico", en Pilar Andrade, Arno Gimber y María Goicoechea (eds.), Espacios y tiempos de lo fantástico. Una mirada desde el siglo XXI, Berna, Peter Lang, 2010, pp. 17-30.

—, Tras los límites de lo real: una definición de lo fantástico, Madrid, Páginas de Espuma, $2011 \mathrm{a}$.

- "Exploradores de lo (ir)real. Nuevas voces de lo fantástico en la narrativa española", Boletín de la Biblioteca Menéndez Pelayo, LXXXVII (2011b), pp. 295-316.

_- "El monstruo posmoderno: nuevas estrategias de la ficción fantástica", Pasavento. Revista de Estudios Hispánicos, I.1 (2013), pp. 7-10.

_, "El reverso de lo real: formas y categorías de lo insólito", en Javier Ordiz (ed.), Estrategias y figuraciones de lo insólito en la narrativa mexicana (siglos XIX-XXI), Berna, Peter Lang, 2014, pp. 7-29.

Sánchez Aparicio, Vega, "Horrores generacionales: visiones de la derrota en los relatos de Patricia Esteban Erlés y David Roas”, Brumal. Revista de Investigación sobre lo Fantástico, 1.2 (2013), pp. 201-221.

Sánchez Villadangos, Nuria, "Lo fantástico frente a lo real y lo grotesco en los cuentos de Patricia Esteban Erlés", Tropelías. Revista de Teoría de la Literatura y Literatura Comparada, 23 (2015), pp.473-486.

Todorov, Tzvetan, Introduction à la littérature fantastique, Paris, Seuil, 1970. 
Truffaut, François, El cine según Hitchcock, Madrid, Alianza Editorial, [1966] 2016.

Varga Llamazares, Raquel de la, "Mujeres que matan. Dimensiones del monstruo en la narrativa de Patricia Esteban Erlés", en Natalia Álvarez y Ana Abello (coords.), Espejismos de la realidad. Percepciones de lo insólito en la literatura española (siglos XIX-XXI), León, Servicio de Publicaciones de la Universidad de León, 2015, pp. 233-242.

Velasco Vargas, Magali, El cuento: la casa de lo fantástico. Cartografía del cuento fantástico mexicano, México, Fondo Editorial Tierra Adentro, 2007. 
